\title{
A constituição da consciência ambiental na interação dos sujeitos uns com os outros e com os recursos naturais
}

\author{
Jairo Marchesan ${ }^{1}$ \\ Otavio Aloisio Maldaner ${ }^{2}$ \\ Maria Cristina Pansera de Araújo ${ }^{3}$
}

Resumo: Este artigo busca entender a formação da consciência ambiental em pequenos agricultores familiares e as relações que estabeleceram entre si e com os bens naturais (solos, águas e matas) em sua trajetória histórica, política e econômica. Pressupõe-se que o ser humano se constitui em processos interativos, conforme a abordagem histórico-cultural de matriz vigotskiana. A pesquisa realizou-se no município de Concórdia, localizado na Mesorregião Oeste Catarinense, colonizada a partir de 1920 por descendentes de alemães e italianos provenientes das "colônias velhas" do estado do Rio Grande do Sul. Foram entrevistados doze agricultores (colonos). Eles são sujeitos participantes ativos desse processo e, no senso comum, são considerados os poluidores e degradadores dos recursos naturais. Procurou-se entender, à luz do modo de produção capitalista e de suas necessidades, como os sujeitos sociais dessa área de grande intervenção humana e intensa exploração econômica enxergam a modificação do meio e a formação da consciência ambiental.

Palavras-chave: Abordagem histórico-cultural. Educação Ambiental. Sustentabilidade ambiental.

Environmental consciousness formation in the interaction of subjects with each other and with natural resources

Abstract: This paper studies the formation of environmental consciousness in small farmers and their relationship to each other and to natural resources (soil, water and forests) in their historical, political and economic development. Following Vygotsky's historical and cultural approach, it is assumed that human beings constitute themselves in interactive processes. Research took place in the city of Concórdia, located in Western Santa Catarina, since 1920 settled by descendants of Germans and Italians from the "old colonies" of the State of Rio Grande do Sul. Twelve farmers have been interviewed. They are active participants in this process and, in the environmental common sense, they are considered to be natural resources polluters and degraders. Under the light of the capitalist production mode and its needs, we tried to understand how social subjects living

\footnotetext{
${ }^{1}$ Professor na Rede Púb. Est. de Ensino e da Univ. do Contestado/Concórdia (SC). jairo@netcon.com.br

2 Professor do PPG em Educação nas Ciências da Unijuí (Univ. Regional do NO do Est. do Rio Grande do Sul) - Ijuí. maldaner@unijui.edu.br

3 Professora do PPG em Educação nas Ciências da Unijuí (Univ. Regional do NO do Est. do Rio Grande do Sul)-Ijuí._pansera@unijui.edu.br
} 
in this region of human intervention and extensive economic exploitation see environmental changes and environmental consciousness formation.

Keywords: Historical and cultural approach. Environmental Education. Environmental sustainability.

\section{Introdução}

O processo de colonização da Mesorregião do Oeste Catarinense (Sul do Brasil), mais precisamente do município de Concórdia, hoje Microrregião do Alto Uruguai, acontece a partir de 1920 com a entrada de descendentes alemães e italianos provenientes das denominadas "colônias velhas" do estado do Rio Grande do Sul. A região era habitada por indígenas e caboclos, com os quais se estabeleceram conflitos pela posse da terra. Os nativos foram, gradativamente, eliminados ou afastados para outras regiões. A "implantação" desses colonos em pequenos lotes rurais, numa região desconhecida e de difícil acesso, contribuiu para estabelecer determinadas relações sociais e ambientais, obrigando-os a explorar os recursos naturais à exaustão. Isso, associado às atividades econômicas (agricultura e agropecuária), gerou problemas ambientais (desmatamento, degradação e erosão dos solos, poluição das águas superficiais e subterrâneas) que são sentidos intensamente ainda hoje.

Este artigo procura compreender, através da trajetória histórica, política e econômica de pequenos agricultores familiares do Oeste Catarinense, as relações estabelecidas entre si e com os bens naturais (solos, águas e matas) e a formação da consciência ambiental que começa a se expressar nas últimas décadas. Tendose por base a abordagem histórico-cultural, parte-se do pressuposto de que o ser humano constitui sua especificidade em processos interativos, entre os quais as formas inteligentes de lidar com o meio na busca da sobrevivência. De acordo com Luria (1988, p. 25),

[...] a inteligência é uma função psicológica superior e, portanto, constituída nas interações sociais e as origens das formas superiores de comportamento consciente deveriam ser encontradas nas relações sociais que os indivíduos mantêm com o mundo exterior.

$\mathrm{Na}$ investigação, ouviram-se, em conversas e entrevistas semiestruturadas, doze pessoas (colonos) do sexo masculino, com idades entre 49 e 82 anos, pertencentes às etnias alemã e italiana, que moram na região estudada de 30 a 75 anos e que foram participantes ativos do processo de colonização, já que contribuíram para a degradação ambiental. Nove são agricultores/colonos

${ }^{4}$ Denominação atribuída às primeiras regiões colonizadas do estado do Rio Grande do Sul, ainda no século XIX, por imigrantes europeus e seus descendentes (alemães e italianos). Destacam-se as regiões do Vale do Rio dos Sinos, Rio Taquari e Rio Caí. A dimensão de uma colônia dessas regiões era de 50 ha. 
idosos, aqui nominados Colonos 1, 2, 3, 4, 5, 6, 8, 9 e 10. Além deles, foi entrevistado um sindicalista (Colono 7) e os Colonos 11 e 12 pertencentes a organizações de produção agropecuária orgânica. Os critérios de inclusão foram: i) participantes do processo de colonização e/ou seus descendentes diretos com lembranças de relatos do início do processo ou que manifestavam visão histórica mais ampla; ii) possuírem diferentes compreensões no entendimento da realidade vivida; iii) nova consciência na relação com os recursos naturais; iv) práticas agrícolas mais sustentáveis e produção agroecológica.

As entrevistas realizadas com os colonos balizaram-se em vinte questões sobre o cotidiano desses sujeitos nas suas relações com os recursos naturais. No entanto, neste artigo, foram analisadas apenas oito delas: 1) Quais as principais recordações do passado desta região em relação às terras, as águas e as matas? 2) A partir da vivência, das lembranças e do que diziam as pessoas mais idosas, descreva como era ambientalmente esta região antes da colonização. 3) Por que e como se deu o processo de ocupação e colonização desta região? 4) Como você percebeu o desenvolvimento da região? 5) Quais as principais alterações, transformações ambientais do espaço regional? 6) A partir da sua vivência e do que diziam as pessoas mais velhas, estabeleça comparações entre viver e produzir - passado e atual. 7) Aponte os principais benefícios e malefícios do processo de modernização da agricultura. 8) Quais as suas principais conclusões, constatações e reflexões ambientais sobre o espaço regional?

As entrevistas foram gravadas em áudio, com a autorização prévia dos participantes, e consideradas como fontes documentais de acordo com Lüdke e André (1986). Elas foram transcritas e lidas exaustivamente para identificar as percepções e concepções dos sujeitos sobre os recursos naturais e a degradação ambiental, decorrentes do processo produtivo em que se envolveram ou ainda estão envolvidos. Isso permitiu revelar a consciência ambiental que as pessoas produziram em sua história de vida. Trechos representativos das entrevistas ilustram a categoria central de análise: a constituição da consciência dos colonizadores e dos agricultores atuais, cujos resultados e discussões são apresentados nos próximos itens.

\section{Constituição da consciência de colonizadores no processo de colonização com abundância de recursos naturais}

As relações econômicas de produção influenciam e, por vezes, até determinam a constituição da consciência dos sujeitos sociais, pois condicionam determinadas relações e práticas sociais e com o ambiente. Nas análises sobre as percepções e concepções produzidas, constatou-se que não são apenas os fatores econômicos que determinam a ação desses sujeitos sobre o ambiente, são também os afetivos, os ligados à necessidade de sobrevivência, os biológicos, psicológicos, comunicativos, históricos e geográficos. Com base nos pressupostos teóricos adotados, se aceita que as ações e vivências concretas formam a consciência, seja coletiva, seja individual. As vicissitudes enfrentadas 
durante os primeiros anos do processo de colonização de uma região acidentada, como é a do Vale do Rio Uruguai, no Oeste Catarinense, são inúmeras. Os colonos dessa região defrontaram-se com as seguintes dificuldades: acesso ao lote de terra; instalação inicial e construção de suas moradias; falta ou precariedade dos meios de transporte; escassez de recursos econômicos, de instrumentos de trabalho e, por vezes, até de víveres. Isso os levou a constituir consciências de confronto com os recursos naturais, numa perspectiva de "vencer a natureza", com práticas de exploração dos mesmos na busca da sobrevivência.

A derrubada de uma mata adulta, exuberante, densa, secular, coberta por imbuias, araucárias, cedros, angicos, grápias, canelas e outras espécies, era vista como necessária ao cultivo tradicional de grãos. A organização das primeiras roças, com o uso de ferramentas rudimentares, como foice, machado, serrote de mão e cunha, concretizava a tecnologia disponível na época. Essa é uma condição importantíssima a ser considerada, pois influenciou muito a concepção que o colono passou a ter em relação à vegetação ou à natureza como um todo. O exemplo da derrubada da mata ilustra o trabalho árduo e extenuante despendido, bem como o sofrimento suportado na lida para derrubar, queimar, retirar e, às vezes, transportar as toras de madeira para fora da roça, por meio, basicamente, do esforço físico humano e da tração animal.

As concepções desses sujeitos em relação aos recursos da natureza constituíam-se de modo dicotômico: um bem, que fornecia material para a construção das casas e galpões, e, paradoxalmente, um obstáculo, que impedia a sua instalação para gerar outros bens, recursos financeiros e, principalmente, excedentes. O discurso do Colono 1 ilustra esse paradoxo e o do Colono 2 estabelece um paralelo entre o passado e o presente, mostrando a necessidade de devastar a mata para conseguir subsistir e viver.

Lá tinha terra nova para trabalhar à vontade, mata para se derrubar. A terra, ela correspondia, tu plantava, colbia, não precisava se preocupar com a adubação que nem boje. Então, a terra correspondia ao agricultor e o custo da produção era barato, porque não precisava investir na agricultura. Então, naquela época, se ganhava dinheiro trabalhando na roça [...] aqui era uma terra boa, terra fértil, que produzia, terra que correspondia, então, o povo vinha em busca disso, com esperança de futuro [...] (Colono 1).

Hummm! O que tinha e o que restou. Há áreas corrigidas, migalhas em relação ao que existia na época. Na época tinha fartura de mato... onde foi destruido. Nós era obrigado a fazer para sobreviver, não tinha outra maneira. (Colono2).

O Colono 8, por sua vez, afirma que a chegada da motosserra "foi um desastre; aí o pessoal ia e derrubava a árvore pra ver cair" [...] e, [ainda hoje, os colonos] "não têm lenha [pra serrar] e mato pra derrubar, mas têm motosserra".

Nestas duas últimas falas, já é possível identificar a formação de determinada consciência ambiental, mais crítica, com a mudança do ponto de vista inicial em 
comparação com o atual. Pode-se dizer que as novas necessidades já modificam a consciência atual de colonos, mesmo que tenham participado de forma direta ou não da devastação inicial, pelas necessidades da época.

No transcorrer dos anos, a possibilidade de adquirir e dominar uma motosserra representou a superação do sofrimento, o poder e a supremacia de um colono sobre a vegetação, uma questão ainda viva em sua mente. Porém, novamente, o colono torna-se vítima do mercado pelo consumo desse instrumento e subordina-se ao capital, que requer um consumidor.

Por outro lado, a habilidade do capital, representado inicialmente pelas Companhias Colonizadoras e posteriormente pela ação das agroindústrias, expressa o investimento na colonização desse espaço, tirando daí determinadas produções, eficazes e competentes do ponto de vista do mercado, e, ainda, desenvolvendo uma atividade econômica extremamente lucrativa. Qual é a relação entre o capital e o espaço? Quanto trabalho e exploração ambiental foram necessários para realizar a ocupação e a produção agropecuária exigida? Moreira (1985) ajuda a responder essas e outras questões estreitamente ligadas ao problema investigado.

Monopolista sobre o espaço geográfico, o capital controla os homens e a natureza, para os tornar homens e natureza para o capital. Mediando a relação homem-meio e crescendo sobre ela, o capital tece a "geografia dos homens concretos". E esta geografia da alienação degrada o homem e a natureza [...]. Fomenta a escassez para forjar necessidades novas e renovar as necessidades velhas, subordinando a existência dos homens e os movimentos da natureza ao circuito das mercadorias. (MOREIRA, 1985, p. 106).

Essa resposta encaminhada por Moreira justifica a necessidade de compreender como as pessoas percebem o seu meio e se constituem sujeitos sociais com determinadas práticas coletivamente partilhadas. A abordagem histórico-cultural, adotada neste texto como referencial teórico de análise, é voltada para essa compreensão.

As ações e inter-relações dos sujeitos singularizam-se num processo que vai da intersubjetividade (interpsicológico) para a subjetividade (intrapsicológico). Vigotski compreende, assim, que a constituição do humano específico, que é a consciência de si, estabelece-se do social, inicialmente externo ao sujeito, para o individual, próprio do sujeito, ou seja, dos processos intersubjetivos se constituem os processos intrassubjetivos: "as atividades e relações humanas, somadas às suas condições de existência e historicidade, acabam constituindo e formando a consciência humana" (VIGOTSKI, 1994, p. 69-76).

Para o nosso contexto de estudo, aceitamos que o ser humano, em suas relações com o ambiente e com outros homens, produz alterações no espaço e no tempo, o que resulta na transformação não só da paisagem em si, agudamente visível, mas do próprio homem. Esse é um dos princípios marxistas básicos a partir dos quais Vigotski concebe a constituição do sujeito humano. 
Os colonos entrevistados nem sempre tiveram a dimensão das mudanças ambientais, suas causas e consequências, nem o entendimento de suas ações, muito menos se sentiam responsáveis ou culpados pelos problemas produzidos, no início do processo. Por essa razão, é fundamental problematizar e politizar a questão a partir do processo de colonização e "desenvolvimento econômico" da região, à luz do modo de produção estabelecido e do "modelo econômico" de produção e reprodução do capital em todas as suas esferas, bem como à luz da história dos colonizadores, seus interesses e sua lógica em diferentes tempos e espaços.

A ação de qualquer ser vivo, num determinado meio, obviamente provoca alterações, mas a ação do ser humano no processo produtivo com vistas a gerar excedentes é mais agressiva. Além de satisfazer as necessidades de alimento e abrigo para sua sobrevivência, estabelece relações sociais de convivência, de produção agropecuária e adota artefatos tecnológicos, que demandam mais recursos naturais, para acúmulo e privatização. Nesse processo de produção, ainda se estabelece a luta, a correlação de forças pelos recursos naturais e pelo espaço em si. É preciso, por isso mesmo, estudar e entender o seu tempo, o espaço, vivências, conflitos, práticas, valores e hábitos culturais, bem como suas relações consigo, com os outros e com o meio. Ademais, Vigotski (1994, p. 80), com base nas análises de Engels na Dialética da Natureza, considera que "o homem, por sua vez, age sobre a natureza e cria, através das mudanças nela provocadas, novas condições naturais para sua existência”. Gramsci (1978) acompanha a mesma linha de pensamento e instiga a considerar todos os elementos que constituem um modo de ser do homem em uma determinada civilização. Além disso, afirma:

[...] deve-se conceber o homem como uma série de relações ativas (um processo), no qual, se a individualidade tem a máxima importância, não é, todavia, o único elemento a ser considerado. A humanidade que se reflete em cada individualidade é composta de diversos elementos: 1) o indivíduo; 2) os outros homens; 3) a natureza. (GRAMSCI, 1978, p. 39).

O processo de colonização é a história de uma civilização que, em busca da própria sobrevivência, tira da natureza os bens necessários e passa a ser dependente do mercado, que lhe impõe a forma de se relacionar com o meio. Nesse processo, as pessoas singularizam-se. Logo, podemos afirmar que os colonos são assim porque estabeleceram interações específicas com os recursos naturais desde o processo de colonização da região.

A forma como os indivíduos manifestam a sua vida reflete muito exatamente aquilo que são. O que são coincide, portanto, com a sua produção, isto é, tanto com aquilo que produzem, como com a forma como produzem. Aquilo que os indivíduos são depende, portanto, das condições materiais da sua produção. (MARX; ENGELS, 1980, p. 19). 
Trazidos para o nosso contexto de estudos, os problemas ambientais podem ser percebidos na interação dos sujeitos com o meio, na luta pela sobrevivência e pelas necessidades interpostas nas relações econômicas de produção. Isso denominamos constituição dos sujeitos em processos de interações sociais, alicerçados na compreensão histórico-cultural de constituição da caracterização humana específica.

Isto significa que não se parte daquilo que os homens dizem, imaginam e pensam nem daquilo que são nas palavras, no pensamento, na imaginação e na representação de outrem para chegar aos homens em carne e osso; parte-se dos homens, da sua atividade real. É a partir do seu processo de vida real que se representa o desenvolvimento dos reflexos e das repercussões ideológicas deste processo vital. (MARX; ENGELS, 1980, p. 26).

Nas ações concretas, o homem exterioriza aquilo que já o instituiu em suas funções psicológicas superiores. Por isso, não é possível entender as reações humanas buscando respostas apenas na constituição genética dos sujeitos, é preciso ter em conta a complexidade de sua vida e construção histórica. Ou seja, a formação da consciência do sujeito ocorre mediante as relações e atividades que estabelece em seu meio, em que organismo e meio exercem influência recíproca. Concebe-se, dessa forma, uma mente humana elástica e de natureza histórica, portanto, ilimitada, permitindo que a consciência se torne constitutiva nas relações com o meio e nas inter-relações sociais. Smagorinsky (1995 apud MALDANER, 2000), usa a expressão mente bumana elástica e ilimitada para descrever a capacidade humana de produzir sempre nova consciência na interação com o meio e os outros homens, estendendo-se para além do próprio indivíduo. A mente é, assim, ilimitada espacialmente porque se estende através dos instrumentos de mediação, conectada ao mundo social e cultural em que se desenvolve. $\mathrm{O}$ interacionismo social começa a ser estabelecido no coletivo e acaba sendo assimilado e praticado individualmente em sua consciência e práxis.

Isso leva à reapropriação e depois à interiorização, para dentro do organismo, das propriedades desse ambiente assim transformado (socializado e semioticamente carregado) que produz as capacidades psicológicas superiores que são o pensamento e a consciência humana. [...] A tese geral do interacionismo social, portanto, declara que as propriedades específicas do comportamento humano resultam de uma socialização particular que é possibilitada pela emergência histórica de instrumentos semióticos. (BRONCKART et al., 1996, p. 69).

Segundo Silva (1986), a produção social da consciência ocorre como fenômeno psíquico especificamente humano, de natureza histórica, originado nos processos de trabalho ou nas atividades produtivas, e, por isso, é mister estabelecer conexões entre as relações das atividades cotidianas dos sujeitos e a 
consciência. Para o autor, a atividade, entendida como uma macroestrutura de natureza histórica externa ou prática, estimula o indivíduo a produzir sua existência material ou espiritual. A consciência é considerada como um movimento particular determinado e incluído no movimento externo da atividade humana (SILVA, 1986, p. VIII).

Isso significa dizer que o homem é um ser que se modifica ao interagir consigo, com o outro e com o meio e que, nessa relação dialética, modifica sua própria consciência. Para Santos (1988, p. 87-88), um dos fatores que diferenciam o homem de outras formas de existência e que o tornam um ser "sui generis é o trabalho e sua capacidade reflexiva sobre o mesmo, em que a relação do homem com o meio é um processo sempre renovado que tanto o modifica quanto a natureza".

Quando o homem intervém na natureza, através do trabalho e da técnica, constitui relações que passam a ser ativas e conscientes, possibilitando que se transforme a si mesmo e modifique todo o conjunto de relações do qual é o ponto central. Essa marca do trabalho, do uso da tecnologia e da busca da superação dos condicionantes do ambiente é o que melhor caracteriza o homem do Oeste Catarinense.

\section{Constituição de nova consciência de agricultores em processos agrícolas com escassez de recursos naturais}

Toda atividade humana com profunda relação de dependência de recursos naturais em determinado contexto, como a agricultura, atua fortemente na formação da consciência das pessoas envolvidas. Destarte, a partir do momento em que o mercado exige do homem que acelere a produção, como condição de sobrevivência, as práticas sociais e a relação das pessoas com a natureza produzem transformações, provocando alterações em suas compreensões e, consequentemente, nova consciência social e individual, com o uso mais racional dos recursos naturais ainda existentes, bem como sua recuperação. A realidade atual no Oeste Catarinense é de degradação ambiental e crescente carência de recursos naturais, principalmente devido ao esgotamento das águas superficiais, e isso resulta na perda da qualidade de vida. As compreensões manifestadas por diversos colonos sujeitos da pesquisa ilustram bem as afirmativas anteriores, feitas com base no referencial teórico adotado.

Mas a busca de progresso com granjas de suinos, ela acabou ferindo, digamos assim, o meio ambiente. Hoje nós temos o quê? Rios poluídos, terra que não corresponde mais, não se pensou talvez. muito em conservação do solo, a erosão veio e acabou com as terras. (Colono 1).

As roças se faziam em etapas. Nunca se explorava as terras até o fim, que ela não pudesse se recuperar do verdejo. Se deixava a terra descansar e recuperar, em muitos anos não se plantava num pedaço só. [...] É muito preocupante o 
problema do veneno [...]. O homem se desenvolveu, fez casas, prédios, mas a terra o homem não faz [...]. É algo que a gente tem que preservar. (Colono 2).

Quanto às terras, aqui ninguém falava em adubos [...] foram usadas 50 ou 60 anos sem usar adubos nestas terras. A terra é o sistema de uso também. Faz a lavoura, depois deixa virar capoeira [...]. Outra, a lavoura mal queimada, aquilo era a conservação, nunca queimar demais [...] assim a natureza ia se recuperando. (Colono 3).

Não se explorava a terra até ela não produzir mais, ou ia derrubando o capoeirão lá na frente, mas lá atrás deixava virar capoeirão novamente e assim por diante. Deixava-se a terra descansar. (Colono 4).

Todos os rios da nossa região estão poluidos [...] Hoje, podemos ver, qualquer chuva que der os rios já correm sujos. Hoje, são terras que não servem pra agricultura, nem pra pastagem, apenas pra reflorestamento... Os agricultores estão cada vez mais pobres. Ao invés de progredir, estão regredindo. Os agricultores reclamam por falta de justiça social. Hoje um colono é visto de forma preconceituosa. (Colono 8).

Essas manifestações mostram a existência de problemas ambientais que exigem soluções imediatas para a própria sobrevivência desses colonos no meio em que vivem. Expressam a necessidade de estabelecer novas práticas de produção, formadoras já de uma nova consciência ambiental, mesmo que não saibam quem responsabilizar. Pelas manifestações, depreende-se que eles têm a sensação de serem vítimas de um sistema produtivo que ainda precisa ser entendido. Outros depoimentos reforçam ainda mais as percepções que têm dos problemas decorrentes de práticas agrícolas hiperintensivas para as quais foram empurrados na busca da sobrevivência.

$\mathrm{Na}$ época, o que interessava era ter saúde e poder trabalhar. Nem se interessava tanto pelo dinheiro [...]. Na época um ajudava o outro [inclusive] para fazer as lavouras, o que não era fácil. Era serviço pesado [...] Naquela época se trabalhava e o dinheiro ficava, recuperava o trabalbo. (Colono 5).

Os colonos estão se preocupando [...] o colono se preocupa com a carência das águas, a água se esgotou tanto que hoje a água não tem condições. Tu vai num rio, não tem condições de dar a água para um animal. Porque tá indo tudo no rio. Lá vai o esterco do porco, da vaca, lá vão os agrotóxicos. Então, eu acho que o que mais preocupa a gente é isso ai [...] Mas acontece que eles [capitalistas] confiavam no potencial do agricultor e na cultura que estava nesses imigrantes que vieram para Santa Catarina pra trabalhar, pra produzir, pra se desenvolver e tudo mais. (Colono 6).

Virou um negócio que, desordenadamente, o povo não percebeu. O problema é da poluição [...]. Não adianta produzir poluindo [...] todo problema tem solução. (Colono 8).

Hoje, aqui, por exemplo, não tem mais mato. Então chegou a uma situação que a natureza não devolve mais, porque não tem. Eu queria que tu visse: a nossa fonte aqui secou e nunca tinha acontecido antes. A água sumiu [...] e, se 
chegar faltar água do poço artesiano, vamos buscar água aonde? No Rio Uruguai?... E as águas sumiram! (Colono 10).

Toda a formação histórica desses colonos mostra a luta para solucionar os problemas que originaram, portanto, não são omissos em assumir sua responsabilidade, tampouco em participar na solução desses problemas.

Os últimos depoimentos mostram essa necessidade de conceber, aceitar e adotar novas práticas agrícolas e o manejo dos recursos naturais. Segundo Vigotski (1994), a necessidade mobiliza as pessoas na busca de ajuda para superar obstáculos. Tentativas de se organizar para otimizar essa ajuda, como construir novas parcerias de produção entre os sujeitos, as empresas, as associações, as entidades públicas ou privadas, os sindicatos e as cooperativas, talvez produzam a consciência de romper as relações com o grande capital agroindustrial adotando outras atitudes para com a natureza, as quais deverão estar pautadas por nova postura política, ética, econômica e ambiental. A relação com o ambiente deverá caminhar na perspectiva do desenvolvimento da agricultura e pecuária sustentáveis, como muitos defendem hoje, com vistas à produção ecológica.

A construção de uma nova relação nas formas de produzir não será pela imposição ou exploração de agentes externos, mas pela cooperação constituída nos novos níveis de consciência decorrentes da interação com novos atores. Para a Empresa de Assistência Técnica e Extensão Rural (EMATER/RS, 1997, p. 222),

[...] essa transformação tecnológica não se dá por imposição, mas, sim, pelo esforço consciente e conjugado dos agentes envolvidos (sejam eles técnicos, agricultores ou consumidores) e pelo convencimento - especialmente por parte dos produtores - da viabilidade técnica e econômica das novas tecnologias preconizadas.

A agricultura sustentável poderá gerar maneiras de conceber, relacionar e produzir radicalmente diferentes dos processos conduzidos pelo capital, que, na verdade, acabaram inviabilizando a sobrevivência do agricultor, a qualidade ambiental e a própria qualidade da produção agrícola pelo uso intensivo de agroquímicos sintéticos.

Para ilustrar indícios de mudança nas práticas sociais de organização da produção, destaca-se a iniciativa de quarenta agricultores que fundaram a APRHODIA (Associação dos Produtores Hortifrutigranjeiros de Concórdia), cuja preocupação é a busca da valorização dos seus produtos pelos consumidores. A comercialização direta da sua produção passou a ocorrer semanalmente na Casa do Produtor Rural, construída para esse fim. Eles dispõem de produtos agrícolas sem a adição de agroquímicos artificiais e que são inclusive inspecionados, primando pela qualidade. O trabalho interativo de orientação e incentivo desenvolvido por extensionistas da Empresa de Pesquisa Agropecuária e Extensão Rural de Santa Catarina (EPAGRI) está capacitando, 
qualificando e profissionalizando os agricultores em cursos destinados a construir coletivamente uma nova forma de produzir e comercializar que, está gerando mais empregos e renda na agricultura familiar.

\begin{abstract}
[...] a casa do produtor rural, construida com recursos públicos municipais, foi uma conquista dos pequenos agricultores, que por eles é administrada e nela comercializam os seus produtos [...] A casa é um ambiente adequado para 0 comércio de hortifrutigranjeiros, substituindo assim as tradicionais feiras livres, que eram realizadas nos bairros e nas praças da cidade, considerados espaços impróprios para estas atividades. [...] E crescente a procura por produtos mais limpos e de melhor qualidade, e isto acaba estimulando a profissionalização dos pequenos agricultores e, consequentemente, motivando-os a se manterem no meio rural. (Colono 11).
\end{abstract}

Outra mudança bem-sucedida no município é representada pela APARG (Associação de Pequenos Agricultores de Rancho Grande), que pratica a agricultura ecológica e também comercializa semanalmente seus produtos. Conforme matéria publicada em O Jornal (2000, p. 04), “os agricultores estão provando que é possível cultivar frutas, cereais e hortaliças sem o uso de aditivos químicos e agrotóxicos". O grupo, que decidiu dizer não aos componentes que acabam prejudicando a saúde do consumidor, vem praticando a agricultura ecológica desde setembro de 1994 e é assessorado por agrônomos do CAPA (Centro de Apoio ao Pequeno Agricultor) de Erechim/RS, que também tem o apoio e acompanhamento dos extensionistas rurais da EPAGRI do município. Para o Colono 12, "o desenvolvimento desta modalidade de agricultura se constitui numa alternativa que vale a pena para o pequeno agricultor, que foi e é excluido do processo produtivo competitivista".

Conforme o presidente da APARG, a clientela que busca produtos ecológicos é crescente e o mais importante é incorporar e difundir a consciência ecológica (O JORNAL, 2000, p. 04). Iniciativas como essas demonstram a constituição de uma nova consciência no meio rural e uma alternativa para o homem do campo, satisfazendo o mercado em ascensão.

Nesse sentido, é necessária uma articulação através da educação em relação aos consumidores, por exemplo, de por que é necessário e socialmente melhor consumir produtos locais e produzidos ecologicamente. E buscar formas de criar articulações entre consumidores e produtores que evitem intermediários e signifiquem um benefício comum para ambos os papéis. (RIBEIRO, 1997, p. 154).

Esse modo de produzir motiva novas interações sociais, mobilizando atores com preocupações semelhantes, como os clientes, fornecedores, membros do poder público, entre outros. Isso constitui a consciência com novos sentidos sobre a atividade laboral na busca da sobrevivência com melhor qualidade de vida e ambiental. Pode-se também chamar isso um processo de conscientização 
para a necessidade de produzir de modo mais limpo ou ecológico, evitando as violentas degradações ambientais que o atual modelo econômico impôs. As interações sociais construídas nesses processos, adotando novas práticas produtivas, têm a grande capacidade de enfraquecer estruturas anteriores que mantêm determinado sistema de produção que se mostrou inadequado à nova realidade. Constitui-se, portanto, em processo de ruptura política e econômica com o sistema de produção.

A exigência da formação de nova consciência individual e coletiva, que a lógica anterior não permitia, por desconhecimento das consequências dos problemas a médio e longo prazo ou pela falta de alternativas de autonomia, a qual mantinha os agricultores sob uma tutela de produção e razoável sobrevivência no sistema, é uma realidade.

Os indícios inclusos nas manifestações dos colonos pesquisados apontam esse processo de construção de consciência social e individual desses sujeitos para se relacionarem com o ambiente mantendo uma produção sustentável. A própria história que farão irá qualificar as interações, intervenções e autonomia na tomada de decisões. Assim, a consciência passa para uma dimensão prática, real na vida das pessoas e torna-se capaz de provocar o estabelecimento de outra relação com a natureza e entre as pessoas.

Os agricultores atuais e muitos sujeitos convertidos em produtores agropecuários convivem com uma nova situação em suas relações com os recursos naturais. Considerando a efervescência dos problemas ambientais e os desdobramentos a eles pertinentes, a partir do ano de 2000 o Ministério Público passou a cobrar o cumprimento e/ou a aplicabilidade da Legislação Ambiental a fim de tentar frear os crescentes impactos ambientais.

Diante disso, a FATMA (Fundação de Amparo de Tecnologia e Meio Ambiente), órgão responsável por essas questões no estado de Santa Catarina, amparada pelo Artigo 69 do Decreto 14.250/81, passou a aplicar as Licenças Ambientais $^{5}$ para as atividades econômicas, entre elas a agropecuária, consideradas potencialmente poluidoras. O licenciamento é um instrumento de gestão ambiental previsto na Lei de Política Nacional de Meio Ambiente e em outras normas federais e estaduais. Sua finalidade é garantir a proteção do ambiente e o controle da poluição. A efetivação do Licenciamento Ambiental é

\footnotetext{
${ }^{5}$ Licença Ambiental Prévia (LAP): é preliminar e dada no estágio inicial do estudo de viabilidade do projeto (localização, avaliação econômica, financiamento, incluindo as alternativas). Declara a viabilidade do projeto e/ou localização de empreendimento/equipamento ou atividade quanto aos aspectos de impacto e diretrizes de uso do solo. Se concedida, segue para a Licença Ambiental de Instalação (LAI). Prazo de validade: até dois anos.

Licença Ambiental de Instalação (LAI): pressupõe o detalhamento de Estudo de Impacto Ambiental (EIA). Autoriza a implantação da atividade ou a instalação de qualquer empreendimento/equipamento com base no projeto executivo final. Prazo de validade: até três anos.

Licença Ambiental de Operação (LAO): autoriza o funcionamento do empreendimento/equipamento, atividade ou serviço com base em vistoria, teste de operação ou qualquer meio técnico de verificação. Prazo de validade: até oito anos. Fonte: Fundação de Amparo de Tecnologia e Meio Ambiente (FATMA).
} 
realizada pela FATMA, que libera ou não a licença de localização, instalação, ampliação e operação de empreendimentos e atividades utilizadoras de recursos naturais, considerados efetiva ou potencialmente poluidores ou degradadores ambientais.

Assim, a aplicabilidade da legislação recaiu, mais uma vez, sobre os que produzem ou estão diretamente vinculados ao início da cadeia produtiva: os agricultores. Logo, estes passam a ser os únicos responsabilizados e cobrados com multas por não respeitarem as leis ambientais, como a preservação da cobertura florestal e proteção das águas (rios, nascentes etc.). Portanto, estão numa situação desconfortável e sentem-se lesados de maneira ambiental e econômica nesse processo. Muitos já estão preocupados com a questão e tomaram algumas atitudes para modificar suas ações, mas ainda assim novas pressões são exercidas pela ocupação territorial estimulada pelo modelo desenvolvimentista aplicado na região. As áreas em que os colonos aqui entrevistados moram, segundo a legislação vigente, são impróprias para habitar e desenvolver seu sistema de produção. E, nesse contexto, o que poderão fazer esses sujeitos para se ajustarem às novas exigências?

\section{Considerações finais}

Ao nos aproximarmos dos colonos, tentando compreendê-los em suas práticas, verificamos que suas consciências se estruturaram, tanto em suas relações com o capital (sistema econômico vigente) quanto nas relações com o poder público (Estado), em seus diversos níveis de organização. Nessas relações produzem-se dependências e/ou influências de superestruturas que, por ação direta e ativa ou por omissão, criaram, em determinado momento histórico, situações conflitantes e contraditórias que impedem e/ou dificultam, até hoje, a constituição de novas consciências e, por extensão, não permitem aos sujeitos (colonos) se constituírem e sobreviverem de forma digna nas condições impostas pela roda-viva de ter de atender aos compromissos com agentes do mercado. Ocorre, então, uma dupla dependência (do Estado e do mercado), ao lado de uma realidade ambiental degradada que não mais lhes permite a sobrevivência com qualidade de vida.

A degradação ambiental, decorrente de um contexto histórico e de determinado "modelo" de produção, não é responsabilidade apenas dos agricultores pela superexploração dos recursos naturais. Afinal, eles foram usados e induzidos a agir assim, primeiro como forma de sobrevivência e posteriormente pela única alternativa prática de atenderem aos interesses do capital agroindustrial, inseridos num certo "modelo de desenvolvimento" econômico não concebido por eles, mas que lhes prometia ganhos em enorme escala.

Nestes anos que se seguiram ao estudo, as situações conflitantes continuam, seja porque as rupturas necessárias ainda não foram possíveis, seja porque ainda há poucos sujeitos envolvidos na busca de saídas produtivas promissoras e 
viáveis, conforme evidenciam os casos citados. É viável, por exemplo, a implantação prevista do novo Código Florestal, que possibilita a ampliação das áreas de produção agrícola, comprometendo a proteção aos recursos hídricos?

O estudo mostra, com base nas percepções dos próprios sujeitos envolvidos nas práticas sociais produtivas de sobrevivência, que a produção agrícola intensiva e com vistas à obtenção de excedentes tem causado sérios problemas ambientais no Oeste Catarinense, especialmente no município de Concórdia. Os problemas ambientais são visíveis para qualquer pessoa que tenha contato com essa região, como o desaparecimento das águas e da vegetação original e a contaminação do solo.

No período da colonização da região, a concepção e a relação que os colonos tinham com os recursos naturais era de inesgotabilidade, afinal, a grande disponibilidade destes os credenciava a explorá-los permanentemente sem a preocupação com seu esgotamento. Essa concepção não era exclusiva dos moradores da região em estudo, mas uma visão mundialmente hegemônica. Caso isso acontecesse, pela lógica da colonização, havia a possibilidade de buscar novas fronteiras agrícolas em outras regiões do país, fato que ocorreu com muita intensidade nesse mesmo período histórico. Descartava-se, na época, a possibilidade mais imediata de exauri-los. Prova disso é a exploração compulsória e predatória da água, que hoje é escassa e de baixa qualidade para atender à produção instalada. Se no período da colonização a terra representava para os sujeitos agricultores segurança e prosperidade - "a salvação" -, atualmente significa para eles a "condenação", sinônimo de sofrimento, insegurança e inviabilidade econômica, social e ambiental.

Ouvindo os colonos e seus descendentes, foi possível perceber a grande influência do "modelo econômico" na degradação ambiental, as dicotomias existentes entre trabalho e capital e as inúmeras ações daí provenientes. Nestes termos, cabe o alerta para a superação de análises simplistas, que, normalmente, culpam apenas os agricultores pela degradação ambiental. Não se pode, por certo, isentá-los de toda a culpa pelas atividades executadas, mas se torna fundamental compreender que esses sujeitos, ao produzirem para a sobrevivência e, sobretudo, para o capital, acabaram poluindo e degradando. Todavia, constata-se que eles continuam sendo estimulados a produzir e a agir dessa forma, agora com intenso consumo dos novos produtos tecnológicos, produzindo ainda mais intensamente para garantir a sobrevivência.

Os problemas ambientais são complexos e para compreendê-los foi necessário considerar as condições históricas, econômicas, culturais, geográficas e suas influências na constituição dos sujeitos. A abordagem histórico-cultural adotada permitiu entender o movimento da tomada de consciência dos sujeitos perante os sérios problemas ambientais não resolvidos em um determinado espaço. Denominou-se isso constituição do sujeito nas interações sociais nas quais se acha envolvido. Novas necessidades exigiam ou estão a exigir outras práticas sociais que já se mostram viáveis em determinados contextos.

Sempre de acordo com o referencial teórico de constituição do sujeito, uma nova relação pedagógica deverá ser construída por parte daqueles ligados às 
políticas públicas no espaço rural, como é o caso da EPAGRI, secretarias Municipal e Estadual da Agricultura, escolas de Ensino Fundamental e Médio, movimentos sociais, organizações não governamentais, sindicatos, universidades. Novos sujeitos passariam a ser os mediadores e interlocutores estratégicos, podendo interagir através de um processo educativo contínuo, formal e/ou informal, direto e/ou indireto, a fim de proporcionar e construir coletivamente essa consciência na atividade econômica primária. Em processo formativo de compreensão mais ampla da realidade socioeconômica, os mediadores precisam estar cientes das ações essenciais na relação com os recursos naturais, bem como capacitados a programar e induzir novas formas de produzir, distribuir e consumir os bens agrícolas de acordo com outros modelos de desenvolvimento.

Referendam-se, portanto, a ideia e a possibilidade da aplicabilidade da educação ambiental não formal, em conformidade com a Política Nacional de Educação Ambiental, disciplinada pela Lei Federal n ${ }^{\circ}$ 9.795, de 27 de abril de 1999, expressa em seu Artigo 13: "Entende-se por educação ambiental nãoformal as ações e práticas educativas voltadas à sensibilização da coletividade sobre as questões ambientais e à sua organização e participação na defesa da qualidade do meio ambiente".

A compreensão das práticas concretas demonstra que as ações, conduzidas de maneira interativa por instituições do Estado com a sociedade de um modo geral, possibilitarão a geração de novas consciências. Afinal, não basta sensibilizar, é preciso agir concretamente para que haja redução dos problemas ambientais e melhoria da qualidade de vida das pessoas e da sociedade como resultado de uma construção coletiva.

\section{Referências}

BRASIL. Lei Federal n 9.795, de 27 de abril de 1999. Diário Oficial da União, Brasília, 28 abr. 1999.

BRONCKART, Jean-Paul; CLÉMENCE, Alain; SCHNEUWLY, Bernard; SCHURMANS, Marie-Noëlle. Manifesto: Reformatando as humanidades e as ciências sociais, uma perspectiva vygotskiana. Tradução de Anne Marie Speyer. Revista Brasileira de Educação, n. 3, p. 64-74, set./dez. 1996.

CETAP - Centro de Tecnologias Alternativas Populares. Construindo uma metodologia para o desenvolvimento rural sustentável. In: ALMEIDA, Jalcione; NAVARRO, Zander (Org.). Reconstruindo a agricultura: idéias e ideais na perspectiva de um desenvolvimento rural sustentável. Porto Alegre: UFRGS, 1997. p. 228-239.

EMATER/RS. A agricultura sustentável e a extensão rural: como ampliar a adesão dos agricultores? In. ALMEIDA, Jalcione; NAVARRO, Zander (Org.). Reconstruindo a agricultura: idéias e ideais na perspectiva de um desenvolvimento rural sustentável. Porto Alegre: UFRGS, 1997. p. 217-227.

FATMA - Fundação de Amparo e Tecnologia e Meio Ambiente. Licenciamento Ambiental. Disponível em: 
<http:/ /www.fatma.sc.gov.br/index.php?option=com_content\&task=view\&id=50\&Ite mid=116> . Acesso em: 16 jan. 2006.

GRAMSCI, Antonio. Concep̧ão dialética da história. Tradução de Carlos Nelson Coutinho. Rio de Janeiro: Civilização Brasileira, 1978.

LÜDKE, Menga; ANDRÉ, Marli Eliza Dalmazo Afonso de. A pesquisa em educação: abordagens qualitativas. São Paulo: EPV, 1986.

LURIA, Alexander R. Vigotskii. In: VIGOTSKII, Lev S.; LURIA, Alexander R.; LEONTIEV, Alexei N. (Org.). Linguagem, desenvolvimento e aprendizagem. Tradução de Maria da Penha Villalobos. São Paulo: Ícone, 1988. p. 25-38.

MALDANER, Otavio A. A formação inicial e continuada de professores de química. Professores/Pesquisadores. Ijuí: Unijuí, 2000.

MARCHESAN, Jairo. O Problema Ambiental: Um Processo Sócio-Histórico-Cultural. Espaços da Escola, Ijuí, v. 4, n. 30, p. 19-26, out./dez. 1998.

MARX, Karl; ENGELS, Friedrich. A ideologia alemã I. 4. ed. Lisboa: Presença; São Paulo: Martins Fontes, 1980. (v. 1). (Coleção Síntese).

MOREIRA, Ruy. O que é Geografia. São Paulo: Brasiliense, 1985.

O JORNAL. Edição 1.197, Concórdia, SC, 07 jan. 2000. p. 04.

RIBEIRO, Sílvia. Elementos para uma elaboração sobre o papel das ONGs na agricultura sustentável. In: ALMEIDA, Jalcione; NAVARRO, Zander (Org.). Reconstruindo a agricultura: idéias e ideais na perspectiva de um desenvolvimento rural sustentável. Porto Alegre: UFRGS, 1997. p. 151-161.

SANTA CATARINA. Decreto Estadual no 14.250/81. Cap. IV, Seção III: Da Autorização para a Instalação e Expansão de Atividades Industriais, Comerciais e de Prestação de Serviços. Diário Oficial do Estado de Santa Catarina, Florianópolis, 09 jun. 1981.

SANTOS, Milton. Metamorfoses do espaço habitado. São Paulo: Hucitec, 1988.

SILVA, Maurílio Nogueira da. A produção social da consciência. Uma abordagem histórica da consciência como fenômeno psíquico. 1986. 73 f. Dissertação (Mestrado em Educação) - Faculdade de Educação, Universidade Estadual de Campinas, Campinas, 1986.

VIGOTSKI, Lev S. A formação social da mente: O desenvolvimento dos processos psicológicos superiores. 5. ed. São Paulo: Martins Fontes, 1994. 